\title{
Research on the Optimization Strategy of Shopping Mall Spatial Layout in Hefei Based on Space Syntax Theory
}

\author{
Qinghua Zhou (iD) and Ziqi Liu \\ School of Architecture and Urban Planning, Anhui Jianzhu University, Hefei, Anhui, China \\ Correspondence should be addressed to Qinghua Zhou; zqh1230@ahjzu.edu.cn
}

Received 3 February 2021; Revised 13 March 2021; Accepted 24 March 2021; Published 20 April 2021

Academic Editor: Muhammad Javaid

Copyright ( 2021 Qinghua Zhou and Ziqi Liu. This is an open access article distributed under the Creative Commons Attribution License, which permits unrestricted use, distribution, and reproduction in any medium, provided the original work is properly cited.

\begin{abstract}
Shopping malls are an indispensable part of urban space and an important place for people to spend and socialize, with its internal space being the focus of shopping mall design. This paper studies the internal space of shopping malls using space syntax theory, quantitatively analyzes the three components of the spatial layout of Hefei shopping centers from a rational perspective, and explores the optimization of the spatial combination, node space configuration, and business layout of Hefei shopping centers in order to guide and optimize the internal space of the existing shopping center and provide a certain reference for the future internal space design of the shopping center.
\end{abstract}

\section{Introduction}

Hefei is the capital of Anhui Province. It is located in the middle of Anhui, with a superior geographical location and a long history and culture. Under the guidance of the development goal of "Great Lake City, Innovation Highland," it will be successfully promoted to a new first-tier city in 2020. According to the 2020 City Business Charm Ranking List, Hefei's commercial resource agglomeration has raised three places in a row, making it the fastest rising new firsttier city in the past year. This is mainly reflected in the continuous increase in the total number of brand stores, the steady increase in the strength of the business circle, and the continuous increase in the total daily average passenger flow of the business circle. This phenomenon mostly relies on offline consumption in shopping malls. Offline consumption has greatly increased consumers' requirements for shopping centers. Pleasant shopping space can stimulate consumers' desire to purchase, thereby driving consumption and laying a solid foundation for the commercial operation of shopping centers in the future, thus enhancing commercial vitality.

This article introduces space syntax theory into the research of shopping mall spatial layout. Through the three cases of Swan Lake Wanda, China Resources Vientiane City, and the first-floor space of the Central Shopping Center, a quantitative analysis of the spatial combination, node space configuration, and business layout method is carried out to obtain the optimization strategy of the shopping center space layout.

\section{Research Objects and Methods}

2.1. Research Object. The research object of this article is the spatial layout of the first floor of a shopping mall. There are many elements in the spatial layout of shopping malls, which are composed of streamline organization, format distribution, node space, style and color, lighting effects, etc [1]. The space syntax theory mainly studies "spatial organization," which analyzes and interprets the space of shopping malls from a rational perspective. Therefore, this article mainly conducts research on the spatial layout of shopping malls through the three elements of spatial combination, node space configuration, and business layout. Due to the large number of people on the first floor of shopping malls, a wide range of business types, and the entrance hall space, and the depth of research must be ensured; this article chooses to analyze the first floor space of the shopping mall and its spatial layout. 
2.2. Space Syntax Theory. The theory of space syntax was first proposed in the late 1970s by Professor Bill Hillier [2], a scholar at the University of London. The foundation of space syntax is the topological relationship of space [3]. Through the quantitative analysis of space structure, we can study the relationship between space organization and human society. China has used space syntax theory to study successful cases of shopping malls. Yu Qianbai (2005) pointed out in "Exploring the Public Space Organization of Shopping Malls with Space Syntax" that the public space organization of shopping malls will affect consumer behavior. Using space syntax analysis, it is found that the public space organization of shopping malls is positively related to the flow of consumers. The abovementioned research results also illustrate the feasibility of using space syntax theory to study the spatial layout of shopping malls.

Consumers need to perceive the space through visual observation when consumed in shopping malls [4]. Facing the complex space of shopping malls, it will be more difficult for consumers to find shops and identify directions, which will limit consumers' overall space perception. The view field analysis method commonly used in space syntax theory can study the visible area under the consumers' point of view through a two-dimensional view field, so as to quantitatively analyze the sequence relationship between the visible space and the overall space [5].

2.3. Selection of Spatial Syntax Parameters Index. The parameter index of space syntax is an important part of the space syntax analysis method, which is composed of connection values, depth value, intelligibility, integration, and control value [6]. This article studies the spatial layout of shopping centers. As shown in Table 1, on the basis of satisfying the analysis of the spatial layout components, three parameters of connection value, intelligibility, and integration are selected for quantitative analysis.

The nodal space of the shopping center, as a place where people flow and stay, requires a strong sense of penetration, so as to ensure that the space has a better sense of sequence [7]. The higher the recognition, the more helpful it is to establish the structure of the entire space to strengthen the space guidance [8]. Accessibility affects the vitality of the space and predicts whether the flow of people can reach the target location smoothly.

2.4. Shopping Mall Plane Model Construction. Depthmap is the software for analyzing the relationship of spatial fabrics [9]. It can be used to complete convex map analysis, visibility map analysis, and axis map analysis, so as to perform quantitative and linear analysis of spatial fabrics.

According to the field survey, the floor plan of the shopping center was obtained, and then the floor plan was traced in CAD to draw a concise spatial relationship figure, which was then converted into DXF format and imported into Depthmap software. The view field analysis method is selected to analyze the internal space, and a schematic figure of the parameter values assigned to colors is obtained [10]. The warmer the color, the higher the parameter value will be.
The colder the color, the lower the parameter value will be. The logical relationship of the shopping mall space can be quantitatively analyzed through the parameter value schematic figure [11].

\section{Case Study}

3.1. Case Selection and Basis. According to the field survey of 19 representative shopping centers in Hefei as shown in Table 2, it can be concluded that the spatial combination of Hefei shopping centers is mainly divided into three types: circular, linear, and network.

Linear refers to the arrangement of architectural space along a path, and common spatial combinations include straight, broken, curved, and "L" shapes. Circular means that the building space forms an end-to-end loop as a streamline, usually triangles, quadrilaterals, and circular rings. The network shape refers to the grid-like streamlines formed by intersecting paths in the building space, usually T-shaped, cross-shaped, Y-shaped, and so on.

This paper uses spatial combination as the selection type and spatial node configuration and business type as the selection criteria and selects three cases for analysis. Swan Lake Wanda is a linear space combination method, which is located on the bank of Swan Lake in the government affairs district. It has a superior geographical location and includes a rich variety of business types, forming the commercial center of the government affairs district. China Resources Vientiane City is a ring-shaped space combination, and its streamline organization and architectural space design are extremely varied, and it has a high commercial influence in Hefei. The Central Shopping Center is a network-shaped space combination method. Compared with the other two network-shaped shopping centers, its commercial area is larger and the spatial circulation is more abundant.

\subsection{Case 1: Swan Lake Wanda}

3.2.1. Optimization Analysis of Spatial Combination. The recognizability of the overall space can be reflected by the degree of intelligibility. The higher the degree of comprehension, the easier it is for consumers to understand the functional structure of the space during consumption activities in the shopping center [12]. In this paper, the connection value is the $X$-axis, the global integration is the $Y$-axis, and $R^{2}$ is used to indicate the degree of correlation between the two to get this intelligibility figure. Generally speaking, if $R^{2}$ is greater than 0.5 , it can be considered that the space is easier to understand, and the function distribution of the scattered points represents the magnitude of the intelligibility.

As shown in Figure 1(a), the intelligibility coefficient $R^{2}$ of the first floor space of Swan Lake Wanda is 0.853604, and the scattered points are concentrated and extend above the $X$-axis and $Y$-axis. This shows that the connection value of the first floor of Swan Lake Wanda is highly correlated with the global integration degree and that the spatial structure is clear and coherent [13]; consumers can easily recognize the overall space through local space. 
TABLE 1: Meaning of spatial syntax parameters.

\begin{tabular}{|c|c|c|}
\hline Parameter name & $\begin{array}{c}\text { Spatial } \\
\text { property }\end{array}$ & Meaning \\
\hline $\begin{array}{l}\text { Connection } \\
\text { value }\end{array}$ & Permeability & $\begin{array}{c}\text { The higher the connection value, the more the space connected to its space, and the better the space } \\
\text { permeability. }\end{array}$ \\
\hline Intelligibility & Identification & $\begin{array}{l}\text { The intelligibility refers to the relationship between the local space and the overall space, that is, whether } \\
\text { consumers can judge the overall space through the local space. Comprehensibility is related to } \\
\text { connection value and integration. The higher the connection value and integration, the higher the } \\
\text { comprehensibility. }\end{array}$ \\
\hline Integration & Accessibility & $\begin{array}{l}\text { The degree of integration indicates the convenience of the space. The higher the degree of integration, } \\
\text { the higher the spatial accessibility. In this study, the global integration degree is selected, which } \\
\text { indicates how convenient the node is to connect with all nodes in the entire system. }\end{array}$ \\
\hline
\end{tabular}

TABLE 2: Spatial combination of representative shopping centers in Hefei.

\begin{tabular}{lccc}
\hline $\begin{array}{l}\text { Serial } \\
\text { number }\end{array}$ & Name & Space combination method & $\begin{array}{c}\text { Total construction area (ten thousand square } \\
\text { meters) }\end{array}$ \\
\hline 1 & Binhu Yintai City & Circular & 13 \\
2 & Heart City & Circular + auxiliary moving & 12 \\
3 & line & 10 \\
4 & Cintai Center & line & 13 \\
5 & Anliang City Plaza & Circular & 20 \\
6 & Superbrand Plaza & Circular & 18 \\
7 & Vientiane City & Circular & \\
8 & Datang International Shopping & Network form & 8 \\
9 & Center & Network form & 6 \\
10 & Hong Kong Macau Plaza & Network form & 25 \\
11 & Central Shopping Center & Linear & 20 \\
12 & Baohe Wanda & Linear & 15 \\
13 & Poly Mall & Linear & 7.3 \\
14 & China Resources Ode to Joy & Linear & 8 \\
15 & China Resources Colorful City & Linear & 9 \\
16 & Winbond Intime City & Linear & 10 \\
17 & Swan Lake Wanda & Linear & 12 \\
18 & Wanda Mao & Linear & 15 \\
19 & Yaohai Wanda & Linear & 10 \\
\hline
\end{tabular}

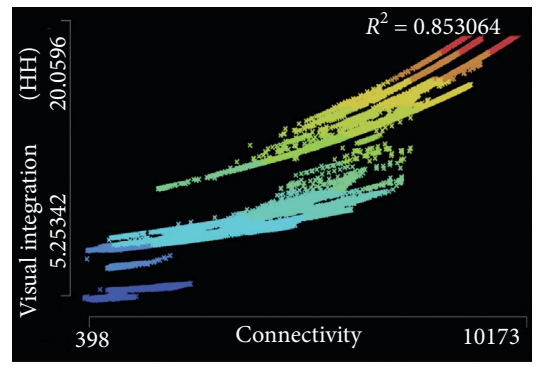

(a)

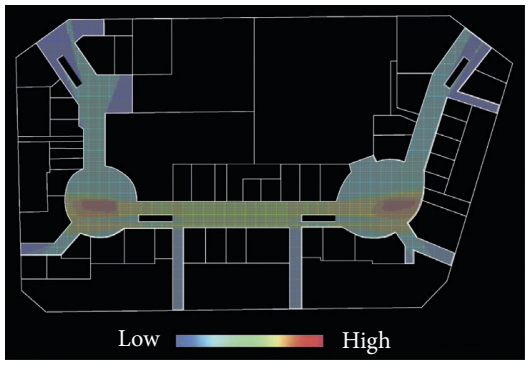

(b)

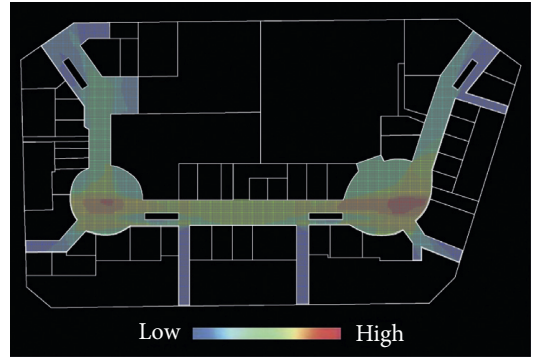

(c)

Figure 1: Analytical view of the first floor of Swan Lake Wanda. (a) Comprehensibility figure. (b) Schematic integration figure. (c) Connection value figure.

\subsubsection{Optimization Analysis of Node Space Configuration}

(1) Traffic Space. It can be seen from Figure 1(b) that the integration of the entrance 1 is blue-green, indicating that the integration of this space is low and that the visibility of the space is low [14]. Through Figure 2(a), we know that the path is designed with a turning point, and an escalator is set up not far from the entrance, which obstructs the line of sight of the space behind the ladder, and the line of sight is not easy to pass directly. The atrium space is the opposite. Part of the atrium has the highest degree of integration, and the rest of the space is moderately integrated, with the atrium 


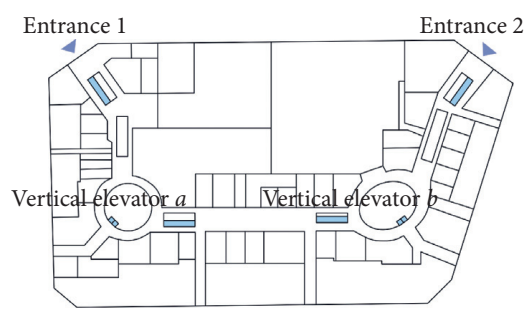

(a)

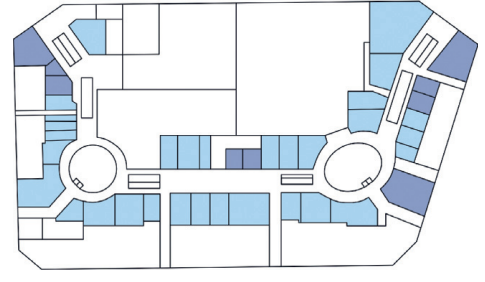

\ Purposeful consumption format Selective consumption format

(b)

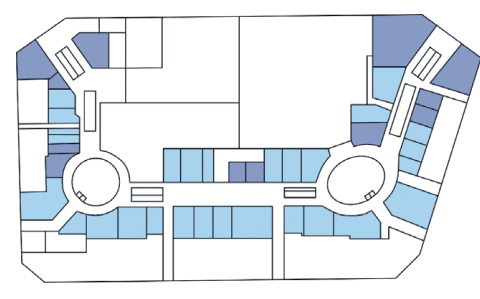

๑ Purposeful consumption format $\square$ Selective consumption format

(c)

FiguRE 2: Schematic figure of optimization of the first floor of Swan Lake Wanda. (a) Schematic figure of the first floor of Swan Lake Wanda. (b) Schematic figure of selective consumption and targeted consumption formats. (c) After optimization, selective consumption and schematic figure of purposeful consumption format.

space being the easiest to attract people. In this space, there are also two main vertical elevators $a$ and $b$ in the shopping mall. The vertical elevators are set up here for high accessibility and can quickly transport consumers to different floors to stimulate consumers' consumption.

As shown in Figures 1(b) and 1(c), the connection value figure of the first floor of Swan Lake Wanda is roughly the same as the integration figure. The connection value of the two atrium spaces is high, and the permeability is high. The circular large atrium space enhances the visibility of the line of sight, and the line of sight is not easily blocked, and a wider range can be seen. The vertical elevator is installed here so that consumers can more easily identify the position of the vertical elevator.

(2) Rest Space. It can be seen from Figure 1(b) that the integration of the two entrance spaces is low and that the flow of people and vitality are low. The addition of rest space in these two spaces can increase the flow of people here [15], which in turn can drive the consumption of surrounding shops. According to field research, there are landscape seats in the entrance 2, and therefore, it is necessary to add rest and residence facilities in entrance 1 , such as seats and landscape sketches.

3.2.3. Optimization Analysis of Business Layout. This paper divides the space into three areas according to the level of integration in Figure 1(b), namely, the red atrium space, the yellow atrium connection space, and the blue-green entrance space.

The first district has the highest degree of integration and the highest accessibility, and there is a high probability that the flow of people will be concentrated in this area. However, the degree of integration in the transition from zone one to zone two differs greatly, indicating that the spatial accessibility of the atrium is not balanced. According to on-site investigations, the atrium space is equipped with kart entertainment facilities and discount display cabinets for clothing. This can quickly drive the vitality of shopping malls and deduct commercial traffic [16], which is more in line with the principle of layout based on integration. The second district has a high degree of integration, high accessibility, and moderate spatial vitality, and the format function is clothing and lifestyle boutiques. As shown in
Figure 2(b), the arrangement of such selective consumer shops can improve commercial convenience. The third district has low integration and poor accessibility. Through Figure 2(c), at the entrance, there should be a purpose-oriented consumptionbased business format and a main store to increase the flow of people.

\subsection{Case 2: China Resources Vientiane City}

3.3.1. Optimization Analysis of Spatial Combination. The intelligibility can be seen from Figure 3(a). The intelligibility coefficient of the first floor space of China Resources Vientiane City is $R^{2}=0.799$, which is not as easy to understand as the linear Swan Lake Wanda first floor space. However, on the whole, it is easier to grasp the overall space through the parts.

\subsubsection{Optimization Analysis of Node Space Configuration}

(1) Traffic Space. According to the result of the syntax calculation in Figures 3(b) and 3(c), the integration degree of the two spaces of entrance 1 and entrance 2 is low and that the spatial accessibility is poor. The connection value figure shows that most of the entrance 2 is blue, showing that its connection value is extremely low. The shops set up here obstruct the view from the entrance to the internal space and have poor permeability. The atrium spaces $\mathrm{A}$ and $\mathrm{B}$ have a high degree of visual integration and high accessibility, and it is easier to attract the attention of people. The escalator set here is also easier to find by consumers. In particular, the spatial integration degree of part A of the atrium space is red, indicating that the degree of integration is high, that the probability of people arriving here is the highest, and that the commercial potential is great. It can be seen that the reachability and permeability of vertical elevators $a$ and $b$ are higher. The reason is that the vertical elevators $a$ and $b$ are close to the main line and are easily found by consumers. However, on the whole, the accessibility and permeability of the vertical elevators are low.

(2) Rest Space. It can be seen from Figure 3(b) that the color of the space on the north side of the first floor of China Resources Vientiane City is green, and its accessibility is low, 


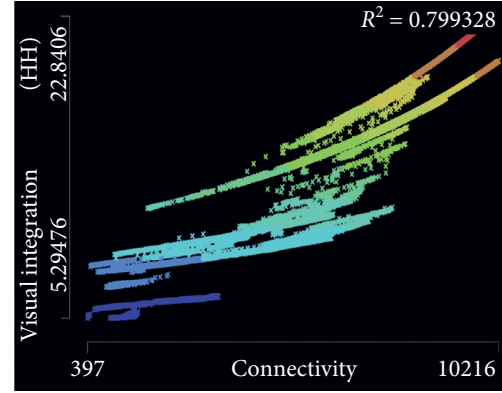

(a)

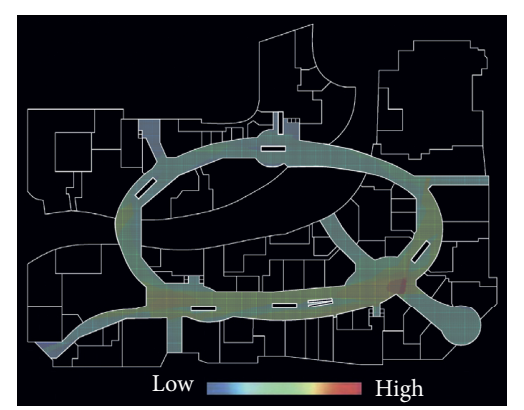

(b)

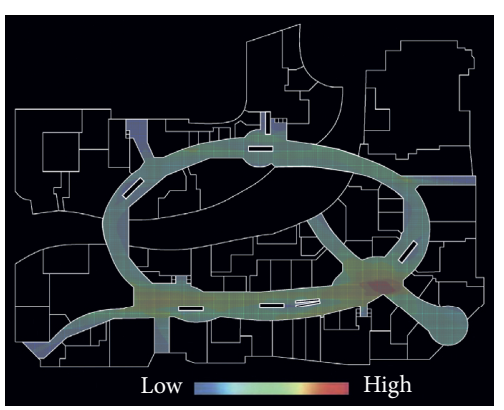

(c)

Figure 3: Analysis of the visual area of the first floor of China Resources Vientiane City. (a) Comprehensibility figure. (b) Schematic integration figure. (c) Connection value figure.

which implies that the flow of consumers is mostly concentrated in the space on the south side. According to the field research, the space on the north side is used as a children's entertainment space through the Thomas Train. This kind of parent-child entertainment greatly enhances the vitality of the space, which is more in line with the principle of using integration to arrange the space. It can be seen from Figure 4(a) that the inner street between the two escalators on the north side has a high integrity and a large space. It is also possible to increase the rest space to attract the flow of people and induce consumer consumption.

\subsubsection{Optimization Analysis of Business Layout.} According to the level of integration in Figure 3(b), the firstfloor space of China Resources Vientiane City has formed two consumption-type areas, namely, the southern space with yellow integration and the northern space with green and blue integration. This can reflect that its commercial integrity is poor, and that the probability of the flow of people reaching the southern and northern areas is quite different. As shown in Figures 4(b) and 4(c), it is possible to set up more targeted consumer shops in the North District and set up selective consumer shops in the South District, which is conducive to the uniform dispersion of the flow of people, making the business vitality generally higher.

\subsection{Case 3: Central Shopping Center}

3.4.1. Optimization Analysis of Spatial Combination. It can be seen from Figure 5(a) that the intelligibility coefficient of the first floor space of the Central Shopping Center is $R^{2}=0.662404$, which is greater than 0.5 . It shows that the positive correlation between the connection value and the global integration degree of the first-floor space of the Central Shopping Mall is not obvious enough and that the recognizability of the space is average. Consumers can grasp the overall space through local space, but will not get lost. Its intelligibility coefficient is lower than those of Swan Lake Wanda and China Resources Vientiane City. It can be seen that the spatial continuity of the Central Shopping Center is not as good as the former two. Its spatial organization seems to be neatly arranged like a network, but due to the large number of intersections, consumers tend to feel confused about the direction and the spatial experience is not high.

\subsubsection{Optimization Analysis of Node Space Configuration}

(1) Traffic Space. It can be seen from Figure 5(c) that the connection value of the three horizontal inner streets is mainly green and some of them are yellow, while the connection value of the four vertical inner streets is mainly blue. The horizontal inner street is divided by the vertical inner street in a large number, and the number of connected spaces is larger. The connection value is larger than the vertical inner street, and the permeability is higher than the vertical inner street. As shown in Figure 6(a), the connection value of the atrium $A, B$, and $C$ is red, the connection value here is the largest in the entire space, the space permeability is the best, and more space can be seen. The five vertical elevators are all set in the hall, and the connection value of the hall is mostly cyan or blue. It can be seen that the installation of five vertical elevators is not easy to be found visually, and the space permeability is low.

It can be seen from Figure 5(b) that the integration of the horizontal internal streets on both sides is yellow and that the integration of the horizontal internal streets in the middle is cyan. It can be seen that the integration value of the horizontal internal streets on both sides is high, and the accessibility is higher than the horizontal internal streets in the middle. In the four vertical inner streets, only the middle vertical inner street has a yellow integration degree and is more accessible. On the whole, there is a greater probability that the consumer flow is distributed in the inner street and atrium space $B$ on the north and south sides, and the probability of attracting the flow is more uniform, but the overall space accessibility is average. The vertical traffic spaces are all set in locations with a low degree of integration, where there is less pedestrian flow and low spatial vitality.

(2) Rest Space. It can be seen from Figure 5(b) that the color of the six entrance halls and the horizontal inner street in the middle is cyan, indicating that the space accessibility here is low and that the space vitality is low. Due to the wide horizontal inner street in the middle, the setting of seats can drive the flow of people. The entrance hall is mostly for 


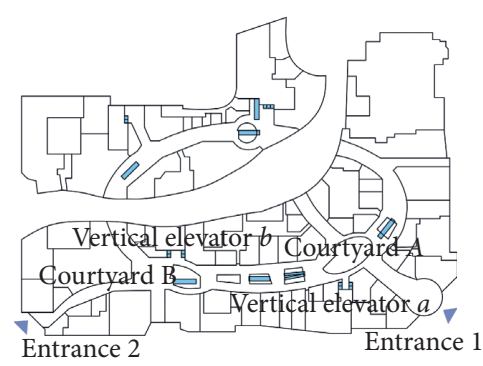

(a)

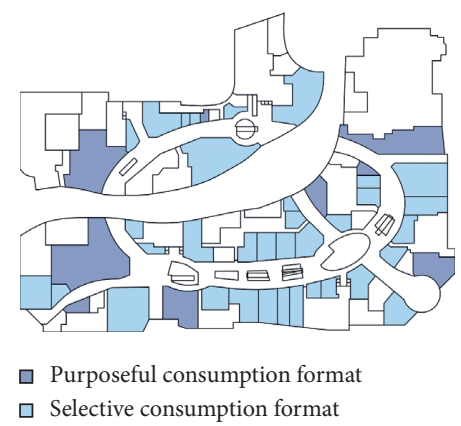

(b)

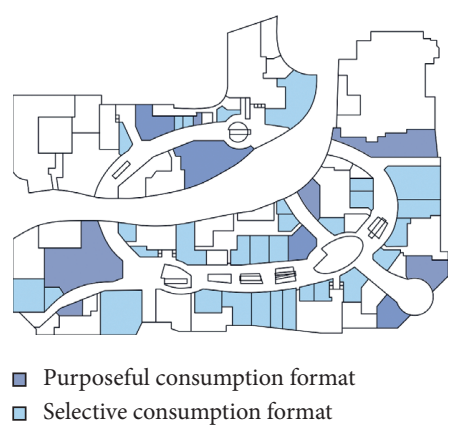

(c)

Figure 4: Schematic figure of optimization of the first floor of China Resources Vientiane City. (a) Schematic figure of the first floor of China Resources Vientiane City. (b) Schematic figure of selective consumption and targeted consumption formats. (c) After optimization, selective consumption and schematic figure of purposeful consumption format.

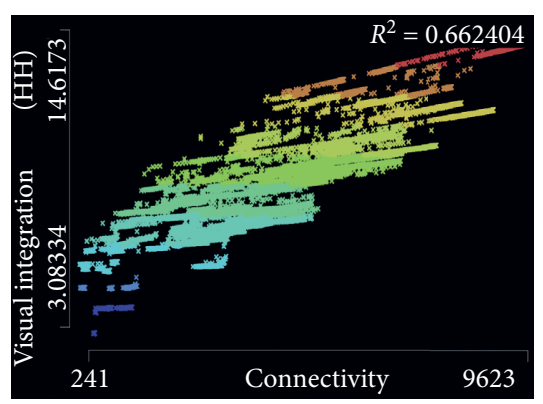

(a)

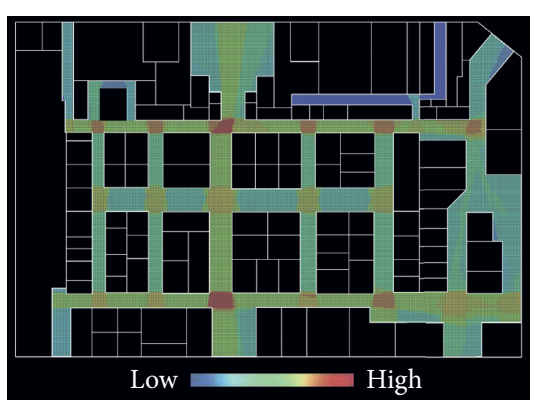

(b)

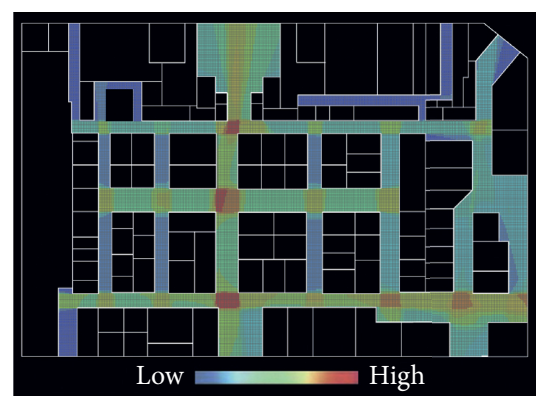

(c)

Figure 5: Analytical view of the first floor of the Central Shopping Center. (a) Comprehensibility figure. (b) Schematic integration figure. (c) Connection value figure.

people to flow in and out of the space, and a good indoor environment can be created with the help of green plants and landscape sketches.

3.4.3. Optimization Analysis of Business Layout. According to the field research, businesses on the first floor of the Central Shopping Center are mainly clothing and footwear. The integration degree of the middle horizontal inner street is cyan, and the accessibility is low. As shown in Figures 6(b) and 6(c), it can attract people by increasing the purpose of consumption format or adding main stores, thereby enhancing the commercial value of the space. The inner streets and atrium space B on the north and south sides of the map with a warmer integration degree have higher integration and the highest probability of attracting people.

\section{Optimization Strategy for Shopping Mall Spatial Combination Based on Space Syntax Theory}

\subsection{Principles of Optimizing the Spatial Layout of Shopping Centers}

4.1.1. Accessibility Principle. The combination of space plays an important role in the organization of the internal space of the shopping center, carries the movement path of consumers, and is also an important way for commercial space layout and connection. Therefore, reasonable selection and design of space combinations can ensure the accessibility of various spaces to the greatest extent and increase consumer experience.

4.1.2. Principle of Identifiability. Vertical transportation space is an important hub of shopping malls, through which consumers go to different floors, where shopping and social activities occur, and they should be placed as easy as possible for consumers to reach.

4.1.3. Principle of Diversity. With the continuous increase in the number of shopping centers, consumers have higher and higher requirements for the space of the shopping center, forcing the space of the shopping center to introduce new ones and avoid repetitive space experience. The principle of diversity can be embodied in the diversity of spatial forms, the diversity of streamlines, the diversity of formats, and the diversity of installations.

4.1.4. Principle of Humanization. Consumers are the main body of shopping center services. The focus of the shopping center spatial layout is not only reflected in the design but also in the principle of "people-oriented." Starting from the 


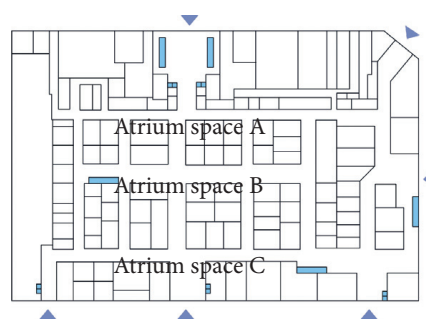

(a)

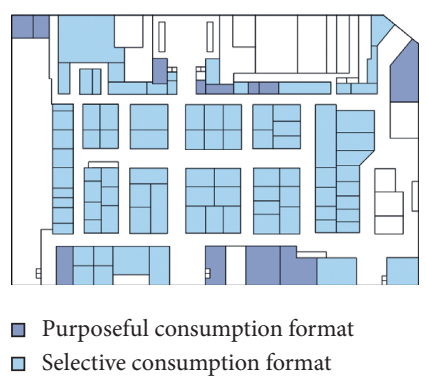

(b)

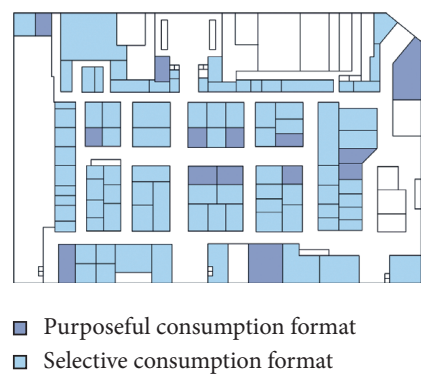

(c)

Figure 6: Schematic figure of optimization of the first floor of Central Shopping Center. (a) Schematic figure of the first floor of Central Shopping Center. (b) Schematic figure of selective consumption and targeted consumption formats. (c) After optimization, selective consumption and schematic figure of purposeful consumption format.

consumers' psychology, it also satisfies consumers' material and spiritual needs.

\subsection{Space Combination Method Optimization Strategy}

\subsubsection{Optimization Strategy of Linear Space Combination.} Linear space is usually assembled by an obvious main line leading the space. This kind of spatial combination is the best in comprehensibility, the spatial structure is clear and easy to identify, consumers can easily grasp the overall space through local space, and the probability of crowd attraction is higher and the distribution is more uniform. However, due to the relatively simple combination of space, the space is unavoidably boring. By arranging the atrium space interspersed with the main line, the integration of the atrium space can be increased to the highest level. In addition, the flexible arrangement of entertainment and other business formats can form a good spatial sequence and enhance the commercial vitality of the shopping center.

\subsubsection{Optimization Strategy of Ring Space Combination.} In shopping malls with circular space combination, the main line is usually connected end to end in a circular shape, and the space is better understood. Consumers can more easily grasp its logic, and it has better mobility compared with linear space combination. However, the side far from the main entrance has a lower degree of integration and lower accessibility, so the atrium space location, shape, and scale should be arranged flexibly to increase the interest of the space and increase the flow of consumers.

\subsubsection{Optimization Strategy of Network Shape Space} Combination. The combination of network-shaped space is usually composed of mutually perpendicular inner streets, which look neat and tidy. However, its intelligibility is the lowest, and there are many spatial intersections, which makes it difficult to distinguish the spatial structure, and consumers are prone to get lost. For locations with a higher degree of integration, the spatial scale of intersections can be expanded and the difference in spatial scales can be increased to improve spatial recognition and form crowded places, or guide signs can be set up to help consumers understand the direction and avoid confusion.

\subsection{Node Space Configuration Optimization Strategy}

\subsubsection{Traffic Space}

(1) Foyer Space. Consumers enter the shopping center through the lobby space, where the first flow of people gather in the shopping center space. From the space syntax analysis, it can be known that if the integration of the lobby space is low, it is difficult for consumers to stay here for a long time. Therefore, it is possible to create a good visual experience in terms of culture, form, and space by increasing the diversity of the lobby space and attracting customers to enter the shopping center. In addition, it is also possible to introduce a purposeful consumer format that is attractive to the flow of people [17] and to increase the main store to enhance the spatial vitality of the shopping center.

(2) Atrium Space. The atrium space can drive the spatial vitality of the shopping mall. From the spatial syntactic analysis, it can be known that the large-scale atrium space becomes the most integrated place. The space here is relatively large, has a strong spatial atmosphere and cohesion, and is the easiest to attract consumers' attention. The smallscale atrium has a general degree of integration and a general probability of attracting people. Therefore, the atrium space of the shopping mall should be arranged flexibly according to the level of integration and enrich the level and change of the space by relying on its form and proportion. In addition, as the atrium space is a temporary profit space, if there is a low integration area, it can appropriately arrange entertainment and other business formats or change the business format ratio of the surrounding stores to reshape the commercial value and achieve the effect of drainage.

(3) Vertical Traffic Space. Consumers rely on vertical elevators and escalators to enter different levels of space, which are an indispensable part of commercial space. Therefore, setting it in a place with a high connection value can be easily discovered by consumers, and it is also conducive to the evacuation and organization of the space. 
4.3.2. Rest Space. The setting of the rest space in the shopping center reflects the principle of "people-oriented." When consumers are exhausted from shopping, the rest space greatly facilitates consumers to stop and rest here. As an auxiliary space of the shopping center, the rest space should consider commercial interests and be arranged in a place with a low degree of integration, so as to gather the flow of people and drive the consumption of the surrounding shops. In addition, it can be equipped with landscape sketches for consumers to watch and optimize the space environment.

\subsection{Optimization Strategy of Business Layout}

4.4.1. Types of Business Formats. According to the service function, the format of shopping center can be divided into retail format, catering format, leisure and entertainment format, and service format. Enriching the types of business formats can satisfy consumers' purchasing desires. Consumers can easily get different experiences when shopping. Different types of business formats can also mutually promote consumption and maximize commercial benefits. We can first analyze the current commercial situation around the shopping center and then determine the composition and quantity of the business based on the type of saturation of the business in the business district, the consumption level of local residents, and the scale of the shopping center.

4.4.2. Business Distribution. Business format distribution can be based on the level of integration value to allocate business formats. Under normal circumstances, where there is a high degree of integration and where there is a large flow of people and high accessibility, the shops here can be equipped with selective consumption formats, such as those with high price tags and high brand level. Shops with low integration have a low probability of gathering here. There should be a purposeful consumption format that can attract the flow of people, such as supermarkets and major stores.

\section{Conclusions}

The development of urbanization in China has brought good development opportunities for shopping malls and has become an indispensable part of urban space. Shopping center is the carrier of consumers' consumption and social activities, and its spatial layout is an important basis for the quality of shopping center space. This article uses the space syntax theory to quantitatively analyze the three cases, explore the optimization principles and optimization strategies of the shopping mall spatial layout, and draw the following conclusions:

(1) The linear space combination method has the clearest space structure. Consumers can easily grasp the overall space through the local space, the ring space combination is the second, and the network space combination is the last.
(2) The lobby of the shopping center can be used to increase the purpose of consumption format, so as to achieve the purpose of drainage. By increasing the scale of the atrium space and appropriately arranging entertainment business formats, the integration of the atrium space can be improved. As far as possible, the vertical transportation space should be placed in a location that is easily accessible to consumers, and rest space should be added at low integration levels to gather people and drive consumption.

(3) The types of business formats should be enriched and balanced, and the location of purposeful consumption and selective consumption formats should be reasonably arranged according to the size of the flow of people.

\section{Data Availability}

The data used to support the findings of this study are included within the article.

\section{Conflicts of Interest}

The authors declare no conflicts of interest.

\section{Authors' Contributions}

All authors contributed equally to this study.

\section{Acknowledgments}

This work was supported by Major Discipline Construction Project of Department of Education of Anhui Province, Research on Multidisciplinary and Multilevel Urban Design Method System Based on Regional Cultural Heritage (gxxk2020-41).

\section{References}

[1] J. Hagberg and A. Styhre, "The production of social space: shopping malls as relational and transductive spaces," Journal of Engineering, Design and Technology, vol. 11, no. 3, pp. 354-374, 2013.

[2] B. Hillier, Space is the Machine : a Configurational Theory of Architecture, Cambridge University Press, Cambridge, UK, 1996.

[3] B. Hillier, "The hidden geometry of deformed grids: or, why space syntax works, when it looks as though it shouldn't," Environment and Planning B: Planning and Design, vol. 26, no. 2, pp. 161-191, 1999.

[4] E. Pafka, K. Dovey, and G. D. Aschwanden, "Limits of space syntax for urban design: axiality, scale and sinuosity," Environment and Planning B: Urban Analytics and City Science, vol. 47, no. 3, pp. 508-522, 2020.

[5] S. Bafna, "Space syntax: a brief introduction to its logic and analytical techniques," Environment and Behavior, vol. 35, no. 1, pp. 17-29, 2003.

[6] Y. Zhang and J. G Wang, "Re-discussion on space syntax," Architects, vol. 3, pp. 33-42, 2004.

[7] S. Bendjedidi, Y. Bada, and R. Meziani, "Urban plaza design process using space syntax analysis:," International Review for 
Spatial Planning and Sustainable Development, vol. 7, no. 2, pp. 125-142, 2019.

[8] P. X. Liu, X. Xiao, J. Zhang, R. H. Wu, and H. L. Zhang, "Spatial configuration and online attention: a space syntax perspective," Sustainability, vol. 10, no. 1, pp. 1-15, 2018.

[9] B. Hillier and J. Hanson, The Social Logic of Space, Cambridge University Press, Cambridge, UK, 1984.

[10] S. K. Jeong and Y. U. Ban, "Computational algorithms to evaluate design solutions using space syntax," ComputerAided Design, vol. 43, no. 6, pp. 664-676, 2011.

[11] X. Li, Z. Lv, Z. Zheng, C. Zhong, I. H. Hijazi, and S. Cheng, "Assessment of lively street network based on geographic information system and space syntax," Multimedia Tools and Applications, vol. 76, no. 17, pp. 17801-17819, 2017.

[12] I. Omer, "Using space syntax and Q-analysis for investigating movement patterns in buildings: the case of shopping malls," Environment and Planning B: Urban Analytics and City Science, vol. 44, no. 3, pp. 504-530, 2017.

[13] L. P. Zheng, C. Sun, L. Liu, and L. Wang, "Wandering crowd simulation based on space syntax theory," Computer Aided Drafting, Design and Manufacturing, vol. 22, no. 2, pp. 68-73, 2012.

[14] B. Hillier and Q. Sheng, "The now and future of space syntax," Architectural Journal, vol. 8, pp. 60-65, 2014.

[15] K. Zaleckis Kamičaitytè-Virbašienè, J. KamičaitytèVirbašienè, and I. Matijošaitienè, "Using space syntax method and GIS-based analysis for the spatial allocation of roadside rest areas," Transport, vol. 30, no. 2, pp. 182-193, 2015.

[16] H. Han, N. Sahito, T. V. Thi Nguyen, J. Hwang, and M. Asif, "Exploring the features of sustainable urban form and the factors that provoke shoppers towards shopping malls," Sustainability, vol. 11, no. 17, p. 4798, 2019.

[17] M.-F. Lin, S.-G. Shih, and Y.-H. Perng, "Sustainable shopping mall rehabilitation," Sustainability, vol. 12, no. 17, p. 6698, 2020 . 